\title{
Análise do custo do ciclo de vida do lastro ferroviário na estrada de ferro Vitória Minas
}

\author{
Fernando Sgavioli', Liedi Bernucci², Robson Costa ${ }^{3}$, Rosângela Motta ${ }^{4}$ e Edson Moura ${ }^{5}$
}

\begin{abstract}
Resumo: Na última década o gerenciamento da infraestrutura ferroviária no Brasil teve grandes mudanças em comparação com as décadas precedentes. $\mathrm{O}$ aumento do volume de mercadorias transportadas exigiu a reestruturação das ferrovias e tornou a gestão da infraestrutura uma questão importante. Como resposta as empresas ferroviárias passaram a trabalhar com ferramentas para análises quantitativas dos impactos de decisões de manutenção, para garantir a qualidade da infraestrutura em longo prazo e sustentar suas necessidades de orçamento. Neste trabalho foi desenvolvida uma abordagem baseada no custo do ciclo de vida do lastro ferroviário em função da variação das premissas do ciclo de desguarnecimento e do ciclo de socaria, a fim de propor uma estratégia de manutenção mais econômica para a Estrada de Ferro Vitória Minas (EFVM). Os estudos obtiveram que a solução de renovação de $50 \%$ do lastro é a mais econômica e os principais custos envolvidos são trem hora parado e socaria.
\end{abstract}

Palavras-chave: Lastro ferroviário. Custo do ciclo de vida.

\begin{abstract}
In the last decade the management of railway infrastructure in Brazil had major changes compared to the previous decades. The increased volume of goods transported demanded the restructuring of railways and infrastructure management became an important issue. In response the railways began working with quantitative analysis of the impacts of decisions on maintenance to ensure the quality of infrastructure in the long term and sustain your budget needs. In this paper an approach based on life cycle cost of the ballast due to changes in the assumptions of the undercut cycle and tamping cycle in order to propose an economic strategy for the asset maintenance at Estrada de Ferro Vitoria Minas (EFVM). The studies have reported that the renewal solution with $50 \%$ of ballast is the most economical and the main costs involved are stopped train hours and tamping

Keywords: Railroad ballast. Life Cycle Cost.
\end{abstract}

\section{INTRODUÇÃO}

O entendimento da estrutura de custos da ferrovia é essencial para planejar o desempenho operacional. A construção, renovação e manutenção dos ativos necessitam de um conhecimento detalhado dos custos envolvidos para estabelecer a tarifação adequada para o tráfego de cargas e passageiros (Profillidis, 2001).

Economistas têm tido interesse na estrutura de custos das organizações ferroviárias a um longo tempo. Borts (1960) e Waters (1985) referem-se a um trabalho realizado no final do século XIX sobre o assunto. A estimativa de custos ferroviários tem uma história de mais de 100 anos, com a literatura acadêmica sendo dominada principalmente por estudos realizados nos Estados Unidos com base em séries temporais, com foco em questões como produtividade, economias de escala e a utilização da capacidade no mercado de frete daquele país (Borts, 1960; Griliches, 1972;

1Fernando Sgavioli, Vale S.A.(fernando sgavioli@hotmail.com) 2Liedi Bernucci, Departamento de Engenharia de Transportes PTR.Escola Politécnica da Universidade de São Paulo - EPUSP. (liedi@usp.br)

${ }^{3}$ Robson Costa, Departamento de Engenharia de Transportes PTR.Escola Politécnica da Universidade de São Paulo - EPUSP. (costa.robsonc@gmail.com)

${ }^{4}$ Rosângela Motta, Departamento de Engenharia de Transportes PTR.Escola Politécnica da Universidade de São Paulo - EPUSP. (rosangela.motta@usp.br)

5 Edson Moura, Departamento de Engenharia de Transportes PTR.Escola Politécnica da Universidade de São Paulo - EPUSP. (edsondemoura@usp.br)

Manuscrito recebido em 18/08/2015 e aprovado para publicação em 19/10/2015.

Este artigo é parte de TRANSPORTES v. 23, n. 4, 2015. ISSN: 2237-1346 (online). DOI: 10.14295/transportes.v23i4.981

TRANSPORTES v. 23, n. 4 (2015), p. 5-12
Keeler, 1974; Oum e Waters, 1996). A maioria destes estudos é movida por um interesse em regulamentar o mercado ferroviário dos Estados Unidos.

A Agência Nacional de Transportes Terrestres (ANTT) publicou, em 2011, resoluções que visam aumentar a utilização das capacidades das malhas ferroviárias existentes. A proposta prevê a revisão de procedimentos relativos ao compartilhamento de infraestrutura ferroviária e de recursos operacionais nas operações de direito de passagem e tráfego mútuo do subsistema ferroviário federal, visando sua integração operacional. Para que isto seja possível a estrutura de custo das ferrovias deve visar a separação entre os custos da infraestrutura e de operação. Dentre os custos da infraestrutura, a superestrutura da via permanente contempla a provisão de orçamento para a manutenção do subleito, lastro, dormentes, trilhos, fixações, sinalização, telecomunicação, instalações elétricas, passagens em nível e infraestrutura para estações de passageiros, além de equipes de manutenção.

O lastro ferroviário é parte importante deste sistema, devido aos processos de manutenção envolvidos, contudo o cenário atual de planejamento de manutenção e renovação da via permanente, onde se inclui o lastro, ainda é baseado em experiências e estimativas (Indraratina, 2010). Dentro deste contexto, verifica-se a importância do tipo de análise denominada "Life Cycle Cost" ou Custo do Ciclo de Vida, doravante chamado somente de LCC.

O LCC constitui um somatório de estimativas de custo, desde a concepção até a baixa de uma atividade, por meio de um estudo analítico e de uma estimativa do total de custos envolvidos durante a vida de tal atividade (Korpi, 2008). O objetivo de uma análise de LCC é escolher a melhor aproximação de uma série de alternativas para que o menor custo de longo prazo seja atingido (Zhang, 2008). 


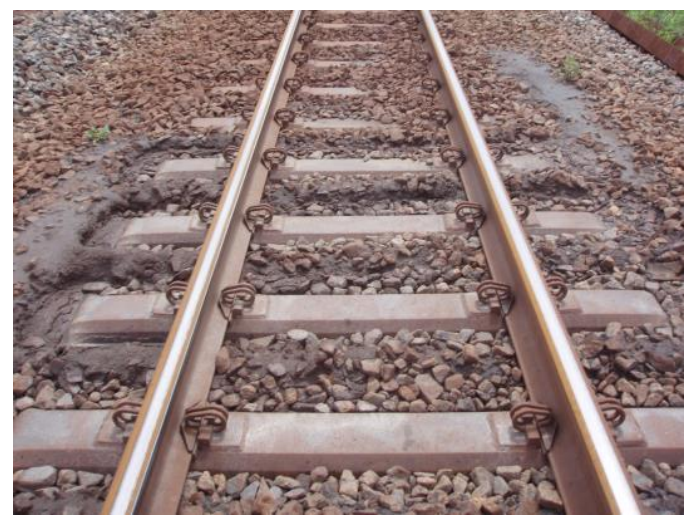

Figura 1. Lastro contaminado por minério de ferro na EFVM

Este trabalho objetiva realizar um estudo de LCC para o lastro ferroviário da Estrada de Ferro Vitória Minas (EFVM), identificando os custos envolvidos no processo de manutenção de lastro. Há duas limitações importantes a considerar neste trabalho. A primeira é que a análise foi realizada para as etapas de manutenção e operação da ferrovia, mas o LCC pode ser realizado para outras fases como projeto, produção do material, etc. Nestas etapas também podem ser verificadas alterações nas características dos materiais e do processo. A segunda é que a confiabilidade da via permanente deve ser estudada para as alterações propostas no processo, de maneira a assegurar que serão preservados os limites técnicos dos materiais, sobretudo a vida útil do lastro e dos dormentes e, consequentemente, a segurança operacional.

\section{CICLO DE VIDA DO LASTRO FERROVIÁRIO}

As principais funções do lastro são: suportar e distribuir uniformemente às camadas inferiores de sublastro e subleito as tensões verticais que ocorrem na interface dormente/lastro, decorrentes da passagem dos veículos; garantir a estabilidade da grade ferroviária perante as forças laterais, longitudinais e verticais; prover alta capacidade drenante; permitir um perfeito nivelamento dos trilhos; dotar a via de resiliência adequada; amortecer vibrações e ruídos; facilitar a conservação, remodelação e renovação da via férrea (Diyaljee, 1987).

No caso desta pesquisa, a apresentação do processo de produção e manutenção do lastro ferroviário é usada para identificar os custos envolvidos. A produção, movimentação e transporte do lastro ferroviário devem possuir procedimentos para garantir que o lastro chegue ao destino dentro de parâmetros especificados quanto às suas características físicas. As demandas e especificações são variadas, devendo-se avaliar separadamente cada um dos aspectos, quantificar sua influência e depois verificar a sinergia deste em relação aos demais. A NBR 5.564 (2011), por exemplo, estabelece os requisitos e métodos para ensaio do lastro ferroviário de pedra britada.

\subsection{DESEMPENHO DO LASTRO FERROVIÁRIO}

Ao longo da vida do lastro pode ocorrer colmatação de seus vazios, acarretando em aumento da necessidade de intervenções de manutenção (Anderson, 2008). Os finos contaminantes do lastro têm como fontes identificadas na literatura: fratura e abrasão das partículas do lastro durante a socaria ou ao longo da vida útil; desgaste do dormente de concreto; infiltração dos materiais das camadas granulares subjacentes/subleito ou de materiais da superfície. Alguns estudos reportaram que cerca de $70 \%$ do contaminante é proveniente da própria quebra do lastro (Selig, Collingwood e Field, 1988). Todavia, ferrovias que transportam carvão ou minério de ferro apresentam altas taxas de contaminação provenientes da superfície, como na Austrália, por exemplo, em que 70 a $95 \%$ dos finos se devem ao carvão infiltrado pela superfície e somente 5 a $30 \%$ provêm da fratura dos agregados do lastro (Feldman e Nissen, 2002). Situação similar ocorre nas ferrovias brasileiras que transportam minério de ferro e carvão (Figura 1).

Os finos contaminantes do lastro são definidos como o material passante na peneira de 9,5 mm (Selig e Waters, 1994). Diversos índices de contaminação foram propostos, como o "fouling index (FI)" de Selig e Waters (1994) (Tabela 1), calculado por meio da soma da percentagem (em peso) de material passante na peneira de 4,75 $\mathrm{mm}\left(\mathrm{N}^{\circ} 4\right)$ e $0,075 \mathrm{~mm}\left(\mathrm{~N}^{\circ} 200\right)$.

Tabela 1. Classificação Fouling Index, segundo Selig e Waters (1994)

\begin{tabular}{ll}
\hline Categoria & $\boldsymbol{F I ~ [ \% ] ~}$ \\
\hline Limpo & $<1$ \\
Moderadamente limpo & $1 \mathrm{a}<10$ \\
Moderadamente colmatado & $10 \mathrm{a}<20$ \\
Colmatado & $20 \mathrm{a}<40$ \\
Altamente colmatado & $\geq 40$ \\
\hline
\end{tabular}

Atualmente, a estratégia de manutenção da EFVM planeja a substituição do lastro quando o índice se encontra colmatado, dessa forma a escavação de trincheiras para coleta de amostras (preferencialmente na zona de socaria, entre a camada inferior dos dormentes e o topo da plataforma) e a identificação de problemas no subleito tornam-se imprescindível. A informação da geometria do lastro também auxilia na solução da decisão.

Geralmente, quando se identifica a existência de problemas no subleito, opta-se pela elevação da camada de lastro para diminuir a deformação no subleito. Se, nesta mesma situação, o lastro também encontrar-se altamente colmatado a um ponto em que a drenagem e a geometria estejam debilitadas, o tipo de manutenção requerida será a renovação do lastro, inclusive elevando a altura da camada.

Em suma, a decisão do tipo de manutenção dependerá da fonte predominante de contaminação e, ainda que 
Tabela 2. Fonte de contaminação, solução e expectativa de resultado

\begin{tabular}{lcccc}
\hline Fonte de contaminação & \multicolumn{4}{c}{ Solução } \\
\cline { 2 - 5 } & $\begin{array}{l}\text { Socaria com complementação de } \\
\text { lastro novo e "recalque" da linha }\end{array}$ & $\begin{array}{l}\text { Recuperação com au- } \\
\text { mento da altura do lastro }\end{array}$ & $\begin{array}{l}\text { Renovação de } \\
50 \% \text { do lastro }\end{array}$ & $\begin{array}{l}\text { Substituição de } \\
100 \% \text { do lastro }\end{array}$ \\
\hline $\begin{array}{l}\text { Fratura dos agregados do } \\
\text { lastro }\end{array}$ & Curto Prazo & Não analisado & Longo Prazo & Não analisado \\
$\begin{array}{l}\text { Infiltração de minério de } \\
\text { ferro pela superfície }\end{array}$ & Curto Prazo & Médio Prazo & Médio Prazo & Longo Prazo \\
$\begin{array}{l}\text { Infiltração do sublastro } \\
\text { e/ou subleito }\end{array}$ & Não analisado & Não analisado & Não analisado & Longo Prazo \\
$\begin{array}{l}\text { Falha ao cisalhamento do } \\
\text { sublastro/subleito }\end{array}$ & Médio Prazo & Longo Prazo & Não analisado & Não analisado \\
\hline
\end{tabular}

haja inúmeras soluções, na Tabela 2 são apresentadas algumas possíveis. A EFVM possui elevada taxa de contaminação por minério de ferro e este trabalho se propõe a avaliar as vantagens e desvantagens de cada uma das 4 alternativas indicadas na Tabela 2, além de indicar aquela que seria a mais econômica para esta ferrovia.

\subsubsection{Socaria com complementação de lastro novo e "recalque" da linha}

As deformações verticais ocorridas na via permanente podem ser elásticas ou resilientes (deflexões) e plásticas ou permanentes (recalques). Para manter ambas as deformações dentro de patamares seguros, a EFVM planeja a manutenção com serviço de socaria a cada 180 Milhões de Toneladas Brutas Trafegadas (MTBT).

Segundo a norma europeia EN 13.450 (2.002), a faixa de intervenção (havendo deformações longitudinais) varia de $12 \mathrm{~mm}$ a $19 \mathrm{~mm}$ para situações em que há circulação de trens com velocidades de 60 a $80 \mathrm{~km} / \mathrm{h}$. Esta mesma norma especifica que o limite máximo de recalque não deve ultrapassar $25 \mathrm{~mm}$, o que caracterizaria uma intervenção de emergência, com o risco da segurança da via ser definitivamente comprometida caso extrapolasse tal valor.

Os trabalhos de socaria convencional na EFVM considerados no LCC contam com um passe com dois recalques devido à utilização de dormentes de aço. Considerando-se um levante médio de $25 \mathrm{~mm}$, estima-se um consumo de brita de $60 \mathrm{~m}^{3}$ por quilômetro. Pode-se assim descrever esta atividade iniciando com o deslocamento da grade para a posição desejada (aumento de $25 \mathrm{~mm}$ ) e assim mantida, são criados vazios sob os dormentes, que são parcialmente preenchidos com lastro novo lançado da superfície; as bancas de socaria penetram no lastro, de ambos os lados dos dormentes, socam (vibram por impacto) o lastro duas vezes, preenchendo o espaço vazio criado sob o dormente, restabelecendo suas condições de apoio na nova posição.

\subsubsection{Recuperação com aumento da altura do lastro}

A atividade de recuperação é recomendada quando a grade ferroviária se encontra em final de vida útil, quando o lastro está colmatado e com altura inferior a $35 \mathrm{~cm}$. Basicamente, têm-se os serviços de recuperação da geometria e do lastro ferroviário, associados à substituição de dormentes, trilhos, acessórios de fixação, para fornecer uma sobrevida até que a linha seja desguarnecida. O serviço de recuperação para a linha principal da EFVM considera um consumo médio de lastro de $500 \mathrm{~m}^{3}$ por quilômetro de linha, em um levante médio de $100 \mathrm{~mm}$.

\subsubsection{Renovação do lastro (50\% e 100\%)}

O lastro deve ser limpo para remover a parte fina, a fim de restaurar sua elasticidade e suas propriedades de drenagem. A limpeza de lastro compreende a remoção da sujeira acumulada, do minério de ferro e do lastro quebrado/desgastado, havendo complementação com lastro novo.

A desguarnecedora substitui o lastro parcial ou total por meio de um sistema de dispositivo de arado com correntes, que passa por debaixo da grade, traz o lastro até uma correia transportadora que, por sua vez, o conduz a peneiras vibratórias, possibilitando uma seleção granulométrica das pedras. Respectivamente para a renovação de $50 \%$ e $100 \%$ do lastro, o serviço de renovação parcial apresenta um consumo médio de $900 \mathrm{~m}^{3}$ e $2.100 \mathrm{~m}^{3}$ por quilômetro de linha.

A deposição do rejeito é o ponto chave na operação da desguarnecedora de lastro. Considerando-se as condições nominais da seção transversal do lastro da EFVM, a desguarnecedora gera um volume de rejeito de 700 a 2.000 $\mathrm{m}^{3}$ por quilômetro. A deposição deste material pode ser feita de três maneiras: (i) deposição do rejeito na lateral da via; (ii) acúmulo do material em um vagão ou (iii) deposição do material em um vagão específico para acúmulo de rejeito. Este último ainda serve de transporte de brita para reguladoras de lastro pois dispõe de pirâmide invertida e com um orifício no vértice por onde escorrem, sendo que nesta modalidade de operação o vagão funciona como reserva para a reguladora de lastro, repondo a brita à medida que é necessária.

\subsection{CUSTO DO CICLO DE VIDA DO LASTRO FERROVIÁRIO}

A primeira etapa da análise de LCC foi apresentada no tópico anterior através de quatro alternativas para o processo de manutenção do lastro. O LCC inclui todos os custos que são viáveis, devendo-se considerar as mudanças necessárias para cada caso específico. Para que as atividades do estudo de LCC fossem elaboradas seguiu-se o fluxo da Figura 2. 


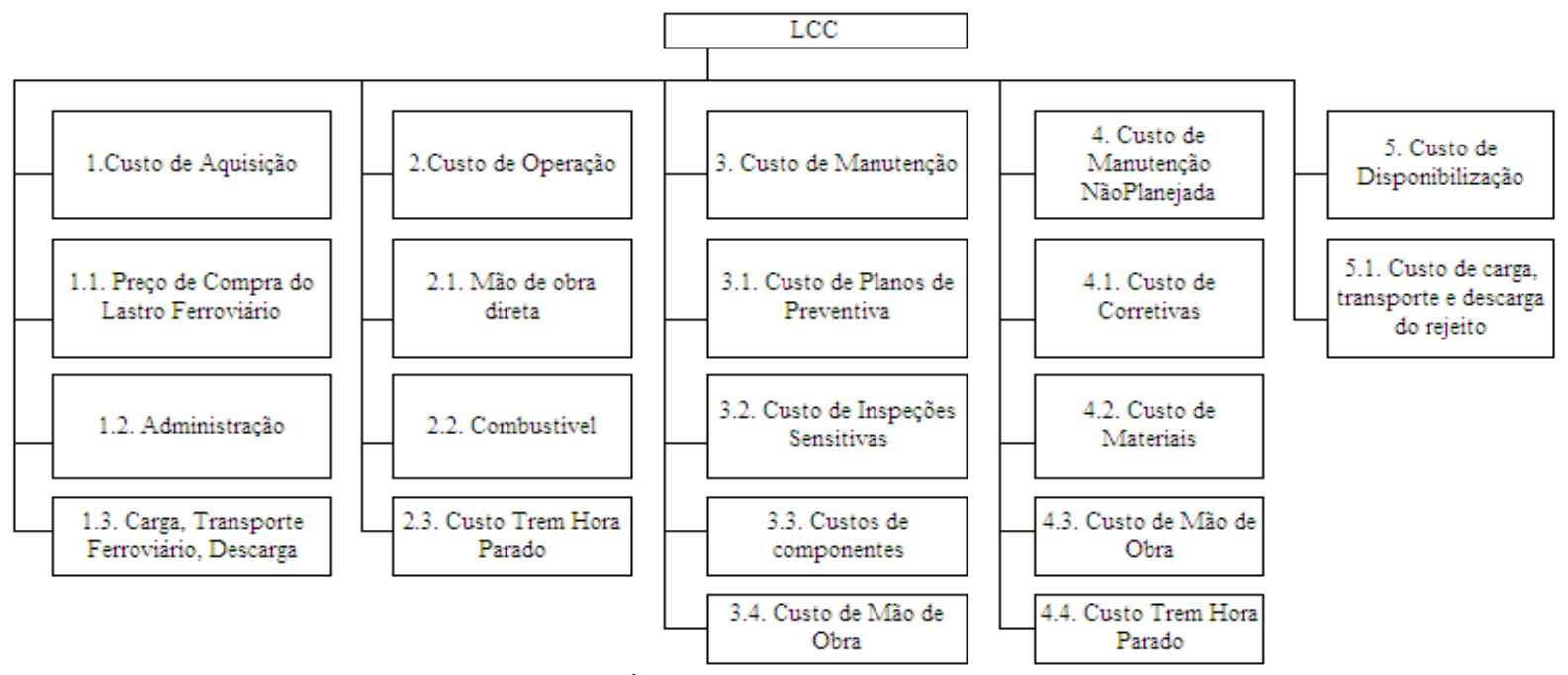

Figura 3. Árvore de desdobramento de custos

Neste ponto vale ressaltar a importância da análise de LCC para a EFVM, pois esta suporta a justificativa da seleção de equipamentos e processos baseados no custo total, e não apenas no custo de aquisição inicial. Geralmente, os custos de operação, manutenção e descarte do ativo excedem todos os outros custos.

Um conceito importante para uma análise de LCC é o Valor Presente Líquido, ou "Net Present Value (NPV)". O NPV é a fórmula matemático-financeira capaz de determinar o valor presente de pagamentos futuros descontados a uma taxa de juros apropriada, menos o custo do investimento inicial. Basicamente, é o cálculo de quanto os futuros pagamentos somados a um custo inicial estariam valendo atualmente.

Normalmente, as decisões atualmente são pautadas não mais na comparação de custos de alternativas, mas sim na avaliação de custos e benefícios. Os benefícios podem ser obtidos através de previsões. Aliado ao custo de ciclo de vida está o desempenho das máquinas e/ou equipamentos, o qual deve ser analisado. Os equipamentos considerados neste trabalho foram os mesmos, para permitir uma análise comparativa das alternativas.

\section{3. ÁRVORE DE DESDOBRAMENTO DE CUSTO E COLETA DAS ESTIMATIVAS}

A segunda etapa consiste no estudo das alavancas de custos existentes em cada uma das alternativas de análise. A identificação e classificação conforme a árvore de desdobramento da Figura 3 permite a investigação das fontes de custos altos e dos riscos envolvidos.

\subsection{COLETA DAS ESTIMATIVAS DE CUSTO}

A etapa de coleta das estimativas de custo é considerada a mais importante do estudo de LCC, devido ao tempo desprendido para o levantamento de custos históricos de cada solução estudada, bem como dos custos projetados para as alternativas estudadas. Neste caso, as fontes consultadas para os custos de manutenção foram o Sistema Máximo de manutenção utilizado na EFVM, além de documentos técnicos internos que remetiam aos custos do processo desde o ano de 2010 e da consulta de especialistas do processo de manutenção. Para o levantamento do custo de

Tabela 3. Estratégia de manutenção dos equipamentos

\begin{tabular}{|c|c|c|c|c|c|}
\hline & Tipo de Serviço & Socadora & Reguladora & Desguarnecedora & Módulo de rejeito \\
\hline \multirow{4}{*}{ 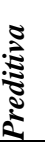 } & Análise de óleo motor diesel & $250 \mathrm{~h}$ & $250 \mathrm{~h}$ & $250 \mathrm{~h}$ & $250 \mathrm{~h}$ \\
\hline & Análise de óleo do sistema hidráulico & $500 \mathrm{~h}$ & $500 \mathrm{~h}$ & $750 \mathrm{~h}$ & $750 \mathrm{~h}$ \\
\hline & Análise de óleo da caixa de transm. hidr. & $500 \mathrm{~h}$ & -- & -- & -- \\
\hline & Análise de óleo do sistema de tração & $500 \mathrm{~h}$ & $250 \mathrm{~h}$ & $750 \mathrm{~h}$ & $750 \mathrm{~h}$ \\
\hline \multirow{9}{*}{ 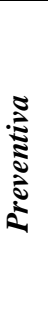 } & Plano preventivo de $125 \mathrm{~h}$ & & & $125 \mathrm{~h}$ & \\
\hline & Plano preventivo de $250 \mathrm{~h}$ & $250 \mathrm{~h}$ & $250 \mathrm{~h}$ & $250 \mathrm{~h}$ & $250 \mathrm{~h}$ \\
\hline & Plano preventivo de $500 \mathrm{~h}$ & $500 \mathrm{~h}$ & $500 \mathrm{~h}$ & & \\
\hline & Plano preventivo de $750 \mathrm{~h}$ & $750 \mathrm{~h}$ & $750 \mathrm{~h}$ & $750 \mathrm{~h}$ & $750 \mathrm{~h}$ \\
\hline & Plano preventivo de $1.000 \mathrm{~h}$ & $1.000 \mathrm{~h}$ & $1.000 \mathrm{~h}$ & & \\
\hline & Plano preventivo de $1.250 \mathrm{~h}$ & $1.250 \mathrm{~h}$ & $1.250 \mathrm{~h}$ & & \\
\hline & Plano preventivo de $1.500 \mathrm{~h}$ & $1.500 \mathrm{~h}$ & $1.500 \mathrm{~h}$ & $1.500 \mathrm{~h}$ & $1.500 \mathrm{~h}$ \\
\hline & Plano preventivo de $3.000 \mathrm{~h}$ & $3.000 \mathrm{~h}$ & $3.000 \mathrm{~h}$ & $3.000 \mathrm{~h}$ & \\
\hline & Plano preventivo de $4.500 \mathrm{~h}$ & $4.500 \mathrm{~h}$ & $4.500 \mathrm{~h}$ & $4.500 \mathrm{~h}$ & $4.500 \mathrm{~h}$ \\
\hline
\end{tabular}

Definição do
problema e
identificação das
alternativas de
análise

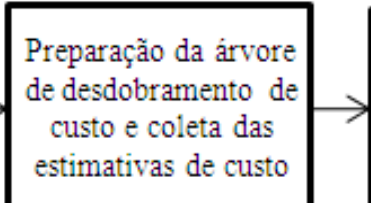

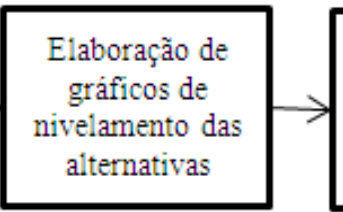


Tabela 4. Estratégia de substituição de componentes

\begin{tabular}{lcccc}
\hline Componente & Socadora & Reguladora & Desguarnecedora & Módulo de rejeito \\
\hline Banca de socaria & $800 \mathrm{~h}$ & -- & -- & -- \\
Caixa satélite & $2.000-6.000 \mathrm{~h}$ & -- & -- & -- \\
Caixa de transmissão & $4.500 \mathrm{~h}$ & -- & -- & -- \\
Caixa de transferência & $6.000 \mathrm{~h}$ & -- & -- & -- \\
Caixa de tração hidr. & -- & -- & $10.000 \mathrm{~h}-12.000 \mathrm{~h}$ & $12.000 \mathrm{~h}$ \\
Diferencial & $6.000 \mathrm{~h}$ & -- & -- & -- \\
Motor diesel & $4.500-9.000 \mathrm{~h}$ & $4.500-9.000 \mathrm{~h}$ & $6.000-12.000 \mathrm{~h}$ & $12.000 \mathrm{~h}$ \\
\hline
\end{tabular}

aquisição do lastro foi usado o valor de fornecimento no Pátio da Tervix em Cariacica/ES, onde há a administração para recebimento e despacho do material por meio de vagões HNE.

O custo de mão de obra de operação e manutenção conta em média com 70 funcionários distribuídos em cargos administrativos, técnicos, topógrafo, operadores e mantenedores. Os equipamentos considerados nas alternativas são desguarnecedora, módulos de rejeito, socadora de linha, reguladora, locomotivas de trens de serviço, pá carregadeira, caminhão comboio, micro-ônibus e caminhonete.

A Tabela 3 apresenta a estratégia de manutenção para estimativa dos custos dos equipamentos, baseados no horímetro, ressaltando a recomendação da utilização do plano de manutenção proposto pelos fornecedores. Há serviços preditivos e preventivos específicos para cada equipamento não seguindo um padrão na Tabela 3 , por exemplo o plano preventivo de $125 \mathrm{~h}$ adequa-se apenas a Desguarnecedora.

A Tabela 4 apresenta os principais componentes utilizados nas manutenções dos equipamentos.

Sobre os custos da manutenção não planejada, devido não haver um histórico com estimativas de confiabilidade da via permanente e dos equipamentos, estes não foram considerados. Já no caso do custo de disponibilização do rejeito do lastro foi utilizada a premissa de uma distância média de transporte de 30 quilômetros.

A projeção dos custos de aquisição, manutenção, operação e disposição para os anos de análise para cada alternativa são atrelados ao volume transportado na ferrovia. Em virtude disso, torna-se necessário o cálculo da projeção de horas que o trem fica parado em função dos serviços planejados para cada alternativa. A EFVM possui diferentes equações baseadas no histórico, e que são analisadas diariamente para minimizar o impacto na circulação dos trens, onde a equação 2 representa o trecho da ferrovia situado no Espírito Santo.

[Trem x Hora] $=1,7889 \mathrm{e}^{0,1035[\text { EHxHora] }}(2)$

Onde:

EH: Entre Hoising (local com quatro aparelhos de mudança de via);

Hora: Quantidade de horas programadas para interrupção de uma linha.

Tabela 5. Premissas para nivelamento das alternativas

\begin{tabular}{|c|c|c|c|c|c|}
\hline Premissas & Unid. & $\begin{array}{l}\text { Socaria com } \\
\text { complementação } \\
\text { de lastro novo e } \\
\text { recalque da } \\
\text { linha }\end{array}$ & $\begin{array}{l}\text { Recuperação com } \\
\text { aumento da } \\
\text { altura do } \\
\text { lastro }\end{array}$ & $\begin{array}{l}\text { Renovação de } \\
50 \% \text { do lastro }\end{array}$ & $\begin{array}{l}\text { Substituição } \\
\text { de } 100 \% \text { do } \\
\text { lastro }\end{array}$ \\
\hline Taxa de dormentes de aço & dormentes $/ \mathrm{km}$ & & 1.650 & & \\
\hline Espaçamento entre dormentes & $\mathrm{m}$ & & 0,61 & & \\
\hline Altura de lastro sob o dormente & $\mathrm{m}$ & & 0,4 & & \\
\hline Largura do ombro do lastro & $\mathrm{m}$ & & 0,4 & & \\
\hline Volume de lastro de projeto & $\mathrm{m}^{3} / \mathrm{km}$ & & $2.159,89$ & & \\
\hline Consumo de lastro para a manutenção & $\mathrm{m}^{3} / \mathrm{km}$ & 60 & 500 & 900 & 2100 \\
\hline $\begin{array}{l}\text { Taxa de reaproveitamento de lastro no } \\
\text { desguarnecimento }\end{array}$ & $\%$ & $100 \%$ & $75 \%$ & $50 \%$ & $0 \%$ \\
\hline $\begin{array}{l}\text { Quantidade de socaria / ciclo de } \\
\text { desguarnecimento }\end{array}$ & unid. & 12 & 3 (1 passe) & 4 (1 passe) & 3 (1 passe) \\
\hline Condição de socaria & passes $/ \mathrm{km}$ & 1 & 3 & 6 & 6 \\
\hline Ciclo de desguarnecimento projetado & MTBT & 2.214 & 1.080 & 1.440 & 1.080 \\
\hline Volume de lastro no final do ciclo & $\mathrm{m}^{3} / \mathrm{km}$ & 2.897 & 2.659 & 2.399 & 2.339 \\
\hline $\begin{array}{l}\text { Volume de lastro novo no } \\
\text { desguarnecimento }\end{array}$ & $\mathrm{m}^{3} / \mathrm{km}$ & 0 & 164 & 959 & 2159 \\
\hline $\begin{array}{l}\text { Volume de rejeito de } \\
\text { desguarnecimento }\end{array}$ & $\mathrm{m}^{3} / \mathrm{km}$ & 738 & 664 & 1.199 & 2.339 \\
\hline Produtividade de desguarnecimento & $\mathrm{km} / \mathrm{h}$ & 0,16 & 0,16 & 0,16 & 0,20 \\
\hline Produtividade de socaria & $\mathrm{km} / \mathrm{h}$ & 0,6 & 0,6 & 0,6 & 0,6 \\
\hline $\begin{array}{l}\text { Horas programadas para descarga de } \\
\text { lastro para o desguarnecimento / km }\end{array}$ & $\mathrm{h}$ & 3,40 & 3,40 & 3,40 & 3,40 \\
\hline $\begin{array}{l}\text { Horas programadas para descarga de } \\
\text { lastro para a socaria / km }\end{array}$ & $\mathrm{h}$ & 0,60 & 0,60 & 0,60 & 0,60 \\
\hline Horas programadas para socaria / km & $\mathrm{h}$ & 1,67 & 1,67 & 1,67 & 1,67 \\
\hline $\begin{array}{l}\text { Horas programadas para desguarneci- } \\
\text { mento / km }\end{array}$ & $\mathrm{h}$ & 6,25 & 6,25 & 6,25 & 5,00 \\
\hline
\end{tabular}




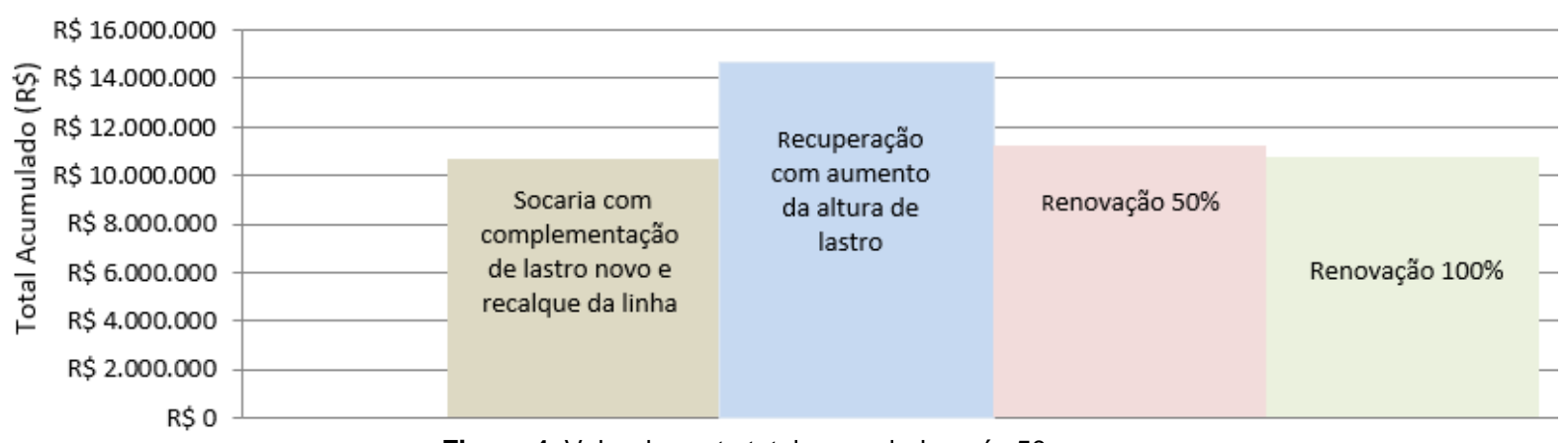

Figura 4. Valor do custo total acumulado após 50 anos

\section{ELABORAÇ̃̃O DOS GRÁFICOS DE NIVELAMENTO DAS ALTERNATIVAS}

Nesta etapa são apresentados gráficos que apontam os custos acumulados de cada alternativa, corrigidos pela taxa de desconto de $12 \%$ para um período de 50 anos. As demais premissas utilizadas estão detalhadas na Tabela 5. Para nivelar as alternativas foram considerados os custos para um quilômetro de linha.

A elaboração do fluxo de caixa possibilitou quantificar a primeira alternativa que remetia a uma solução proposta desde a década de 90 para a EFVM, considerando 12 ciclos de socaria para corresponder a um volume de lastro igual a $40 \%$ de contaminação, e somente então realizar o desguarnecimento. Vale lembrar que a quantidade de socaria estimada para cada alternativa tem o intuito de manter as deformações dentro de parâmetros seguros.
O cálculo do volume de rejeito foi feito visando o retorno ao greide de projeto e, neste contexto, também foi proposto o aumento da produtividade da desguarnecedora devido à diminuição da taxa de reaproveitamento de lastro. Após as considerações das premissas, priorizou-se, na primeira análise, o comportamento do custo acumulado ao longo dos anos, para identificar os pontos onde as alternativas tornam-se mais interessantes. A Figura 4 demonstra o valor total acumulado do fluxo de caixa após 50 anos, onde verifica-se que a atividade de recuperação foi o maior valor acumulado.

A Figura 5 apresenta os resultados relativos ao trem hora parado acumulado que foi calculado pela equação (2), em função das horas programadas para as atividades descritas na Tabela 5, onde a recuperação também apresentou o maior valor acumulado.

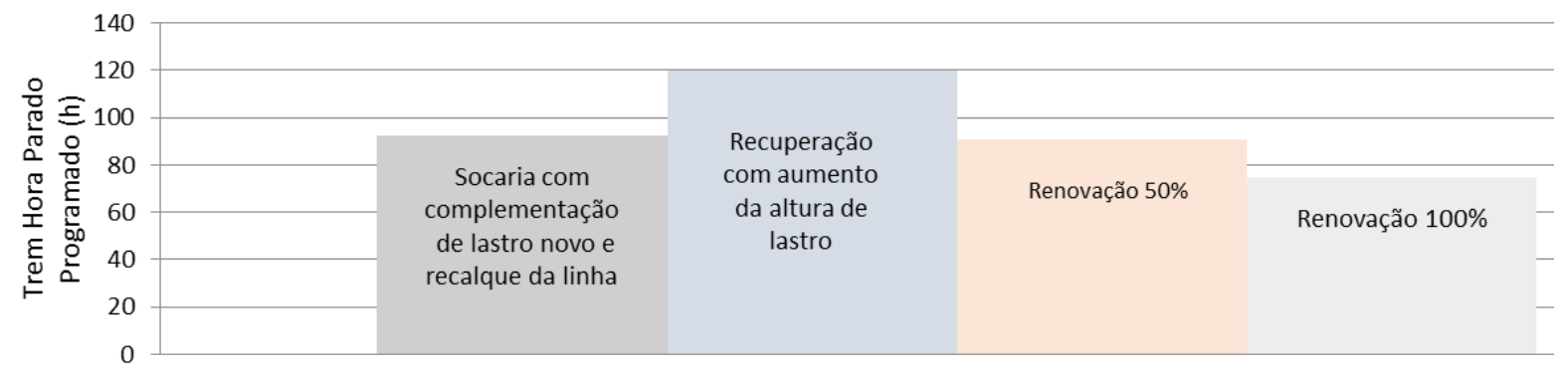

Figura 5. Trem hora parado acumulado após 50 anos

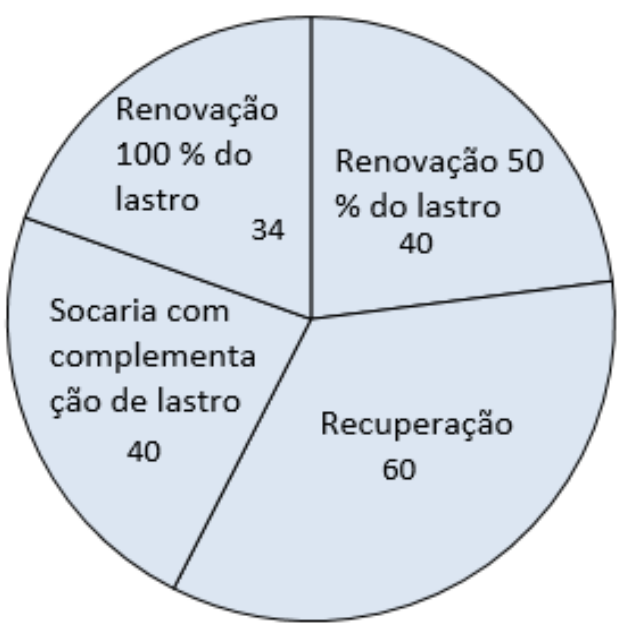

(a)

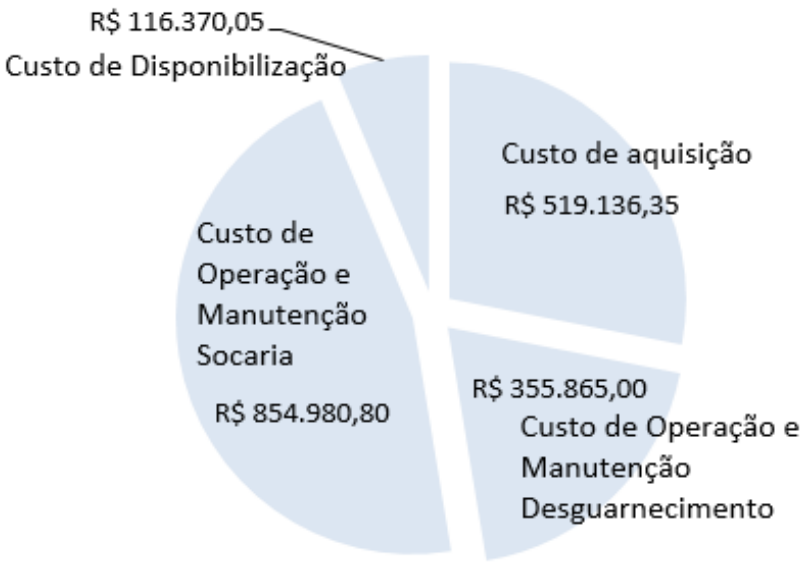

(b)

Figura 6. (a) Quantidade de passes de socaria e (b) Árvore de custos da atividade de recuperação 


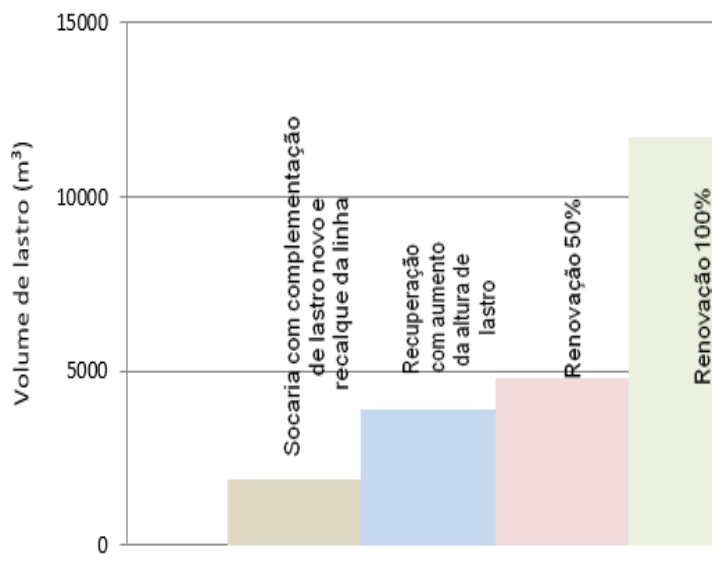

(a)

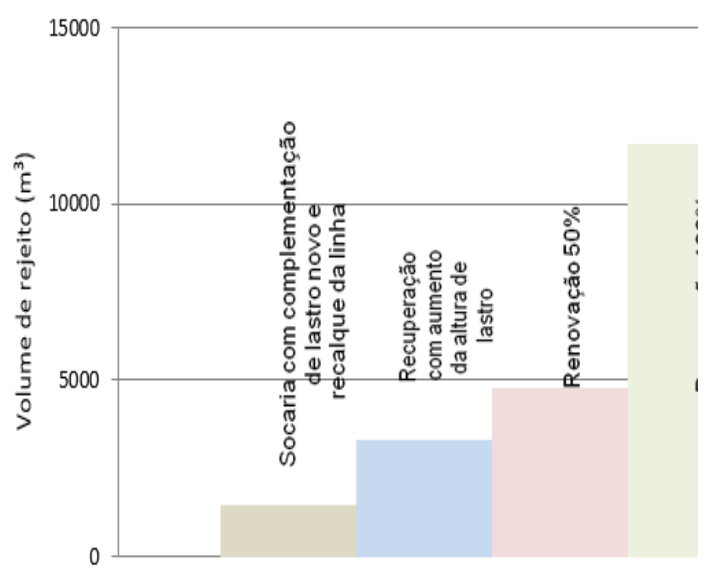

(b)

Figura 7. (a) Volume total de lastro (b) Volume total de rejeito

Tabela 6. Análise comparativa do valor presente líquido

\begin{tabular}{llllll}
\hline & $\begin{array}{l}\text { Correção geométrica com } \\
\text { complementação de lastro } \\
\text { novo e recalque da linha }\end{array}$ & $\begin{array}{l}\text { Recuperação com } \\
\text { aumento da altura } \\
\text { do lastro }\end{array}$ & $\begin{array}{l}\text { Renovação de } \\
\text { 50\% do lastro }\end{array}$ & $\begin{array}{l}\text { Substituição de } \\
\text { 100\% do lastro }\end{array}$ \\
\hline $\begin{array}{l}\text { Custo presente } \\
\text { líquido / km } \\
\text { Custo anual equivalente }\end{array}$ & $\mathrm{R} \$ 1.386 .845,20$ & $\mathrm{R} \$ 1.863 .722,10$ & $\mathrm{R} \$ 1.175 .575,95$ & $\mathrm{R} \$ 1.387 .381,60$ \\
\hline
\end{tabular}

\section{ANÁLISE DOS CUSTOS ALTOS E SUAS RAZÕES}

O custo do trem hora parado representou de $70 \%$ a $90 \%$ do total dos custos das alternativas estudadas, sendo que o mais alto foi o da atividade de recuperação, que também se destacou das demais soluções devido à elevada quantidade de passes por quilômetro de socaria (Figura 6a), sendo cada passe a atividade de elevar a grade efetuando o nivelamento, descer o conjunto de socaria, efetuar o fechamento das ferramentas utilizadas na socaria e consolidar o lastro, elevar a banca de socaria mantendo a linha suspensa pelo conjunto de nivelamento. Em seguida, resultaram os custos de aquisição de lastro (Figura 6b).

A Figura 7 (a) e (b) demonstra que o volume final de aquisição do lastro é proporcional ao de rejeito, justamente pela premissa de retornar a grade ferroviária a altura de projeto após o desguarnecimento. A EFVM consome em média $150.000 \mathrm{~m}^{3}$ de lastro por ano, demonstrando a importância deste estudo.

Finalmente, a Tabela 6 resume o melhor custo presente líquido e o custo anual equivalente para a solução de renovação de $50 \%$ do lastro, considerando todos os custos, dentre eles o do trem hora parado. O risco da ocorrência ou não ocorrência dos custos altos, apontados acima, pode vir a afetar o resultado global da análise. Para tanto, deve ser identificada a probabilidade da ocorrência dos eventos de trem hora parado.

\section{CONCLUSÕES}

$\mathrm{Na}$ análise final, considerando que existem diferenças de desempenho entre as alternativas apontadas, verificase que a solução de renovação de $50 \%$ do lastro é a mais econômica como estratégia de manutenção do lastro da
EFVM. Uma sistemática de verificação das premissas do estudo de LCC deve ser realizada anualmente, devendo ainda ser feita a análise destas premissas sempre que for necessária uma nova decisão relacionada com o estudo, durante o período de validade do LCC.

O principal custo foi o do trem hora parado que de certa forma é inevitável, embora na prática, para minimizar os impactos, tenha se adotado anteriormente a interrupção a priorização de manutenção na linha adjacente a ser desguarnecida, de forma que não ocorram falhas. O custo de socaria, segundo mais importante, apresenta limitações, primeiro porque o projeto da plataforma da EFVM possui limites variando de 20 a $80 \mathrm{~cm}$ do pé do talude do lastro até o bordo das canaletas de drenagem, devendo-se, assim, limitar em 4 recalques para evitar a queda de lastro nas mesmas. Segundo porque é desconhecido o aumento da taxa de defeitos de geometria na EFVM em função do aumento da altura da camada de lastro.

Outro fator referente à socaria reafirma a importância de conhecer como se dão os deslocamentos na via permanente, pois a previsão do momento ideal da intervenção, com a técnica adequada poderá resultar em uma economia para os operadores ferroviários. Neste caso, seria interessante a implantação de um sistema de gerência, com base em levantamento de dados do comportamento da via permanente in situ ao longo do tempo, como forma de avaliação de desempenho. Esta poderia ser realizada, por exemplo, com medidas de deslocamento em campo para a determinação do módulo dinâmico de via, onde este poderia ser um indicador para auxiliar na determinação da necessidade de manutenção em um dado ponto, ao mostrar uma dada variação da resposta do pavimento ferroviário.

Uma próxima abordagem neste tema, não menos importante, é o estudo de impacto ambiental, com análises da emissão de $\mathrm{CO}_{2}$ e o tratamento dos resíduos gerados no processo de manutenção do lastro. 


\section{AGRADECIMENTOS}

À equipe de via permanente da Estrada de Ferro Vitória Minas pelo apoio à pesquisa.

\section{REFERÊNCIAS}

Associação Brasileira de Normas Técnicas. NBR 5.564: Via Férrea - Lastro-Padrão. Associação Brasileira de Normas Técnicas, Rio de Janeiro, 2011.

Anderson, W. F.; Fair, P. Behavior of railroad ballast under monotonic and cyclic loading. Journal of Geotechnical and Geoenvironmental Engineering, v. 134, n. 3, 2008. DOI: 10.1061/(ASCE)1090-0241(2008)134:3(316).

Borts, G.H. The Estimation of Rail Cost Functions. The Econometric Society, New York, NY, U.S.A, 1960.

Burkett G. Crash Attenuator Usage Along 9 Travel Ways and in Work Zones, July 16, 2010. Advanced Highway Maintenance and 10 Construction Technology Research Center, Department of Mechanical and Aerospace 11 Engineering, University of California at Davis. http://ahmct.ucdavis.edu/pdf/UCD-ARR-12 10-07-16-01.pdf. Acesso em: 13/08/2013.

Diyaljee, V. A.: Effects of stress history on ballast deformation. Journal of the Geotechnical Engineering, ASCE, v. 113, n.8, 1987, p. 909-914. DOI: 10.1061/(ASCE)07339410(1987)113:8(909)

EN 13.450. Aggregates for Railway Ballast. European Standard - European Committee for Standardization, Brussels, Belgium, 2002.

Feldman, F.; Nissen, D. Alternative Testing Method for the Measurement of Ballast Fouling: Percentage Void Contamination. Conference on Railway Engineering, RTSA, 101-109, Wollongong, Australia, 2002.

DOI: 10.3850/978-981-07-4948-4_331

Griliches, Z. Cost Allocation in Railroad Regulation. Bell Journal of Economics and Management Science, v.3, n.1, p. 26-41, Australia, 1972.

Indraratna, B., Nimbalkar, S., Christie, D., Rujikiatkamjorn, C., Vinod, J. Field assessment of the performance of a balasted rail track with and without geosynthetics. Journal of the Geotechnical and Geoenvironmental Engineering, v. 136, n. 7, 2010b, p. 907-917.

DOI: 10.1061/(ASCE)GT.1943-5606.0000312

Keeler, T. Railroad Costs, Returns to Scale, and Excess Capacity. Review of Economics and Statistics, v.56, n.2, p. 201-208, Cambridge, U.S.A, 1974.

Korpi E., Life cycle costing: a review of published case studies, Managerial Auditing Journal, v. 23 n. 3, p.240 261, 2008. DOI: 10.1108/02686900810857703
Oum, T.H., W. A Survey of Recent Developments in Transportation Cost Function Research. Logistics and Transportation Review, 1996.

Profillidis, V.A. The Mechanical Behaviour of the Railway Sleeper, Rail International, 1, 25-33, 2001.

Selig, E. T., Waters, J. M. Track Geotechnology and substructures Management. Thomas Telford Services Ltd., Londres, 79, 1994.

Selig, E.T., B.I. Collingwood, and S.W. Field, Causes of Fouling in Track. AREA Bulletin 717, 1988.

Waters, W.G. II. Rail Cost Analysis. Chapter 5 in International Railway Economics (eds. K.J. Button and D.E. Pitfield), Gower Publishing, Aldershot, UK, p. 101-135, 1985.

Zhang, H.; Keoleian, G.A and Lepech, M.D. "An integrated life cycle assessment and life cycle analysis model for pavement overlay systems". Life Cycle Civil Engineering. 2008. DOI: 1680/geot.2007.57.6.527 